\title{
Consumo das tecnologias pelos estudantes do Ensino Fundamental: potencialidade das técnicas qualitativas de pesquisa
}

\author{
Consumption of technologies by Elementary students: \\ potentials of qualitative research techniques
}

\author{
Stela Conceição Bertholo Piconez \\ Rosária Helena Ruiz Nakashima* \\ Régis Luiz Lima de Souza ${ }^{* * *}$
}

\begin{abstract}
Resumo: Esta pesquisa focalizou a integração das metodologias e técnicas qualitativas como forma de aproximação da realidade pesquisada. Como estudo de caso de natureza descritivo-exploratória, teve como embasamento teórico os estudos contemporâneos sobre metodologias qualitativas de pesquisa (BOGDAN; BIKLEN, 1994; SÁNCHES GAMBOA, 2003; FLICK, 2002; dentre outros). As técnicas selecionadas (questionário, entrevista, grupo focal, filmagem e diagrama) captaram dados sobre o tema consumo de tecnologias em uma escola pública da Grande São Paulo, com estudantes do Ensino Fundamental, e permitiram identificar importantes dados sobre esse consumo em três vertentes: consumo de tecnologia para uso pessoal, consumo de tecnologia na escola e conhecimento sobre o descarte do lixo eletrônico. O conjunto de dados quantitativos e qualitativos confirmou o uso das tecnologias digitais caracterizado pelo acesso às mídias sociais. Revelou os desafios de infraestrutura para inserção das tecnologias nas atividades escolares e a consciência ecológica sobre o descarte do lixo eletrônico. A integração de técnicas quantitativas e qualitativas contribuiu para o melhor entendimento do fenômeno pesquisado. Amparado nos estudos referenciados, o tratamento metodológico dos dados favoreceu o processo analítico das representações, permitindo sua análise compreensiva. Possibilitou também o jogo de sentidos que fundamentou a definição de um horizonte ampliado de interpretação. Este estudo concluiu também que a complexidade na busca da qualidade da pesquisa depende mais da lógica das articulações do que das escolhas técnicas, confirmando o valor agregado com o entrecruzamento de perspectivas teórico-metodológicas da pesquisa qualitativa.
\end{abstract}

Palavras-chave: Técnicas de pesquisa qualitativa. Consumo das tecnologias da informação e da comunicação (TIC).

Abstract: This research integrated qualitative methodologies and techniques in order to approximate the reality studied. As a descriptive and exploratory case study, the study had as its theoretical basis contemporary studies on qualitative research methodology (BOGDAN; BIKLEN, 1994; SANCHEZ GAMBOA, 2003; FLICK, 2002, among others). The selected techniques (questionnaire, interview,

\footnotetext{
* Doutora em Educação pela USP. Professora Titular do Departamento de Metodologia do Ensino e de Educação Comparada da USP. E-mail: spiconez@usp.br.

** Mestre em Educação pela Unicamp. E-mail: rosarianakashima@usp.br.

**** Mestre e Doutorando em Educação pela USP.E-mail: regisluiz@usp.br.
} 
focus group, video recording and diagram) were used to collect data about consumer technologies with students from a public elementary school in Sao Paulo. These techniques allowed the identification of important data on the use of technology by students in three areas: consumer technology for personal use, use of technology in school and knowledge about e-waste discard. The set of quantitative and qualitative data confirmed the use of digital technologies characterized by access to social media. The study also revealed the challenges related to the infrastructure necessary for the integration of technology in school activities and about ecological awareness for the disposal of electronic waste. The integration of quantitative and qualitative techniques contributed to a better understanding of the phenomenon studied. The methodological approach of the data supported by relevant studies favored the representations of the analytical process, allowing for a comprehensive analysis. The study also demonstrated that the complexity in finding quality in research depends more on the logic of connections than on the technical choices, confirming the value added to the crossing of theoretical and methodological perspectives of qualitative research.

Keywords: Qualitative research techniques. Consumption of information and communication technology (ICT).

\section{Introdução}

Trata-se de uma pesquisa descritivoexploratória desenvolvida em uma escola pública da Grande São Paulo, em Barueri, com estudantes do $9^{\circ}$ ano do Ensino Fundamental. A metodologia adotada foi desenvolvida em duas etapas. Inicialmente buscou-se o perfil dos entrevistados a partir das variáveis: idade, gênero, fluência digital, uso de computadores e de aplicativos. Para essa etapa foi realizada a tabulação dos dados com posterior análise frequencial. A segunda etapa ocorreu através da análise de conteúdo sobre o tema "consumo", com a qual foi possível a construção de três nucleamentos de ideias (GARNICA, 1997). O primeiro nucleamento destacou o consumo pessoal da internet; o segundo abordou o consumo nas atividades escolares e o terceiro investigou a consciência ecológica dos estudantes sobre 0 descarte de lixo eletrônico.

Esses nucleamentos foram investigados por meio das potencialidades de técnicas híbridas e qualitativas de pesquisa, tais como a utilização do questionário e da entrevista semiestruturada, sob a perspectiva de grupo focal, fazendo uso de filmagem e elaboração de diagramas pelos participantes sobre o tema Consumo das Tecnologias da Informação e da Comunicação (TIC).

Segundo Chizzotti (2003), a adoção de multimétodos de investigação contribui para o estudo de um fenômeno situado no local em que ocorre, procurando tanto encontrar o sentido desse fenômeno quanto interpretar os significados que as pessoas dão a ele. Nesse sentido, a pesquisa buscou em uma escola pública, junto aos adolescentes do Ensino Fundamental, a compreensão das três vertentes, por meio de métodos quantitativos e principalmente qualitativos.

Os objetivos da pesquisa situaram-se em um enfoque sócio-histórico, uma vez que, segundo Bogdan e Biklen (1994), a investigação não se limita em razão de resultados, atentando-se para as questões importantes que surgem no desenvolvimento da pesquisa. A principal finalidade consistiu em compreender comportamentos e posturas sobre o consumo das TIC a partir da perspectiva dos sujeitos da investigação, 
correlacionada ao contexto do qual fazem parte, valorizando os aspectos descritivos e as percepções pessoais.

Os dados recolhidos tiveram formato híbrido, apurados por palavras e imagens adequadas às características de uma pesquisa qualitativa e analítico-descritiva. Citações e imagens retiradas da pesquisa de campo e da transcrição foram indicadas para ilustrar e substanciar a apresentação dos resultados.

Pautando-se nesses princípios, procuramos conduzir esta investigação privilegiando o diálogo entre o pesquisador e os respectivos sujeitos, entendendo que "os campos de estudo não são situações artificiais em laboratório, mas as práticas e interações dos sujeitos na vida cotidiana” (FLICK, 2002, p. 21). De acordo com Minayo (2001), esse modelo de investigação segue o desenho metodológico de uma "pesquisa estratégica", que permite ao pesquisador orientar-se para problemas que surgem na sociedade. Ainda que não preveja soluções práticas para esses problemas, tem a finalidade de lançar luz sobre determinados aspectos da realidade.

Entretanto, cabe aqui destacar que entendemos a pesquisa como um ato que possibilita também transformações sociais por meio da reflexividade pessoal ou conjunta. Tal pressuposto pode, inclusive, gerar novos questionamentos em direção à remodelação de opiniões e tradições envolvidas no fenômeno estudado.

\section{Metodologia}

Nesta pesquisa foram utilizados métodos quantitativos e qualitativos, entendendo-se que os mesmos não se excluem ou se opõem como instrumentos de análise, mas diferem quanto à forma e à ênfase. Ambos trouxeram grande subsídio a este trabalho, num conjunto híbrido de procedimentos de âmbito racional e intuitivo, capaz de trazer contribuições para o melhor entendimento do fenômeno pesquisado.

Tais contribuições se confirmam, quando consideramos que

As diferentes formas de fazer ciência não se esgotam na alternativa quantitativista ou qualitativista. As abordagens científicas não se limitam às duas anteriores: uma abordagem que dá ênfase a objetividade do conhecimento e a explicação dos fenômenos e a outra que aceita a subjetividade dos fenômenos humanos e procura a sua compreensão e interpretação. (SÁNCHES GAMBOA, 2003, p. 395).

A combinação adotada na presente pesquisa foi chamada por Jick (1979) de "triangulação", ou mesmo de validação convergente ou multimétodo, quando foram escolhidas as técnicas qualitativas.

O desenvolvimento da pesquisa foi encaminhado na perspectiva de estudo de caso, com a intenção de compreender uma situação em particular: o consumo de tecnologias por adolescentes do Ensino Fundamental no âmbito das características do próprio ambiente dos sujeitos da pesquisa. Permitiu investigar como o uso de técnicas híbridas de pesquisa qualitativa de certos fenômenos pode ser investigado mais próximo de seus contextos específicos.

A pesquisa foi realizada em uma escola situada em Alphaville, Barueri, região metropolitana da Grande São Paulo. É importante ressaltar que, segundo os dados do Ministério da Educação, o Índice de Desenvolvimento da Educação Básica (IDEB) no ano de 2009 destaca essa escola como uma das melhores do estado de São Paulo. O IDEB considera dois fatores para a apuração do índice: o rendimento escolar (taxas 
de aprovação, reprovação e abandono) e as médias de desempenho na Prova Brasil.

A escola atende atualmente 2377 alunos, distribuídos em três níveis: Ensino Fundamental I e II; Ensino Médio; e Ensino Profissional Técnico de Nível Médio. Possui 63 salas de aula e quatro salas de informática, cada uma com 20 computadores, sendo três delas de acesso aos alunos e uma de acesso restrito aos professores.

O ponto de partida foi o estudo de técnicas de pesquisa qualitativa e o planejamento da coleta de dados. Muitos cuidados foram tomados em relação ao preparo da coleta de dados e da inserção na escola. Foram realizadas reuniões anteriores ao processo de atuação junto aos estudantes, em que os pesquisadores por meio de documentos escolares, visitas à escola e conversas com a coordenação e direção do estabelecimento investigaram os dados de caracterização dos estudantes e dos projetos pedagógicos desenvolvidos com o uso das tecnologias.

Das sete classes de $9^{\circ}$ ano do Ensino Fundamental, uma das turmas foi escolhida por meio de amostra aleatória simples (PARFITT, 2005). Com o objetivo de caracterizar os sujeitos da pesquisa, foi elaborado um questionário que permitiu a coleta de dados sobre a identificação dos estudantes e das percepções acerca das três vertentes deste estudo. Segundo Parfitt (2005), trata-se de uma ferramenta indispensável quando se pretende obter dados primários, de caráter exploratório, sobre as pessoas, seus comportamentos, atitudes, opiniões e conhecimentos sobre um determinado tema. Tal questionário, intitulado "Formulário de Fluência Digital”, foi adaptado do documento elaborado e aplicado em professores do ensino superior, estudantes de graduação e pós-graduação. Para esta pesquisa foram feitas adequações em relação ao tema e à faixa etária. Composto de 23 questões fechadas, o questionário foi aplicado pelos próprios pesquisadores e as questões foram respondidas anonimamente pelos estudantes durante um período de aula.

Como parte do processo de triangulação de métodos foi elaborada uma entrevista semiestruturada, com o objetivo de colher dados que não foram possíveis de coletar somente pelo questionário. Para Lakatos (1996), a preparação da entrevista é uma das etapas mais importantes da pesquisa, requer tempo e exige alguns cuidados, tais como: o planejamento da entrevista, que deve ter em vista o objetivo a ser alcançado; a escolha do entrevistado, que deve ser alguém que tenha familiaridade com o tema pesquisado; a oportunidade da entrevista, ou seja, a disponibilidade do entrevistado em participar da entrevista, que deverá ser marcada com antecedência para que o pesquisador se assegure de que será recebido; e a preparação específica, que consiste em organizar o roteiro ou formulário com questões importantes.

Quanto à formulação das questões o
pesquisador deve ter cuidado para não
elaborar perguntas absurdas, arbitrárias,
ambíguas, deslocadas ou tendenciosas. As
perguntas devem ser feitas levando em
conta a sequência do pensamento do pes-
quisado, ou seja, procurando dar conti-
nuidade na conversação, conduzindo a
entrevista com certo sentido lógico para
o entrevistado. (BONI; QUARESMA,
2005, p. 72).

Essas orientações foram contempladas no planejamento de um roteiro com nove questões principais e oito questões complementares sobre as três vertentes desta pesquisa. Nessa técnica, a interação entre o entrevistador e os entrevistados favoreceu as respostas espontâneas, em que o entrevistador ficou atento para dirigir a discussão tendo como foco o tema principal, fazendo 
perguntas adicionais com o intuito de elucidar questões que não ficaram claras, ou ajudar a recompor o contexto da entrevista (BONI; QUARESMA, 2005). Após a aplicação do questionário, optou-se pelo desenvolvimento da entrevista semiestruturada em um grupo focal. Do universo de 39 participantes, foi utilizada uma amostra aleatória de dez estudantes.

Os estudantes foram reunidos em uma sala indicada pela direção da escola sob a perspectiva de uma reunião. Segundo Iervolino e Pelicioni (2001), a coleta de dados em um grupo focal caracteriza-se fortemente pela tendência humana de formar opiniões e atitudes na interação com outros indivíduos, em contraste com os dados colhidos em questionários fechados em que os sujeitos são convocados a emitir opiniões sobre assuntos que talvez nunca tenham pensado anteriormente.

As pessoas, em geral, precisam ouvir as opiniões dos outros antes de formar as suas próprias, e constantemente mudam de posição (ou fundamentam melhor sua posição inicial) quando expostas à discussão em grupo. É exatamente este processo que o grupo focal tenta captar. (IERVOLINO; PELICIONI, 2001, p. 116).

O desenvolvimento do grupo focal foi de, aproximadamente, 50 minutos. Um dos pesquisadores conduziu as discussões, exercendo a função de solicitar esclarecimento ou aprofundamento de pontos específicos, conduzir o grupo para o próximo tópico quando um ponto já havia sido suficientemente explorado e estimular os participantes mais tímidos (CARLINI-COTRIM, 1996).

Simultaneamente, para registrar a discussão do grupo focal foi utilizada a técnica de filmagem (coleta de dados visuais) e a gravação do áudio, seguindo, com rigor, as normas do Comitê de Ética. De acordo com Pink (2001), é possível explorar o potencial do vídeo para uma abordagem reflexiva na investigação qualitativa. Pinheiro, Kakehashi e Angelo (2005) completam essa ideia ao afirmarem que a filmagem é relevante, pois minimiza a questão da seletividade do pesquisador, uma vez que a possibilidade de rever várias vezes as imagens gravadas direciona a atenção de um ou mais pesquisadores para aspectos que teriam passado despercebidos, podendo imprimir maior credibilidade ao estudo.

Um dos pesquisadores utilizou a câmera móvel para registrar o evento, enquanto o terceiro pesquisador, presente no momento do grupo focal, foi responsável pela observação geral da discussão e pelo registro de informações relevantes para a pesquisa. Sobre esse procedimento, Kindon (2003) ressalta a importância, no processo de investigação qualitativa, de agir como um "observador participante”, e não como um "participante observador".

O grupo focal foi encerrado com a realização de um registro sobre os benefícios e os malefícios da internet e, logo após, a representação por meio de um desenho, caracterizada pela escolha de um animal cujas características mais se assemelhassem à internet. De acordo com Kesby (2000), diagramas podem incorporar palavras ou ser criados inteiramente com representações em que se utilizam papel e caneta. O uso de diagramas em um grupo focal mobiliza a participação dos sujeitos, a fim de compartilhar experiências e desenvolver ideias. Nesse sentido, o autor destaca que, dentro dos grupos, a natureza visual de diagramação facilita o envolvimento dos menos participativos e os ajuda a expressar sua "voz" sem necessariamente exigir que eles "falem".

Após a atuação no campo de pesquisa e transcrição dos dados coletados, o caminho percorrido por meio da reflexão crítica em 
torno da entrevista transcrita e textualizada permitiu, em nível teórico e prático, selecionar trechos/fragmentos dos relatos considerados significativos para o encaminhamento de algumas possibilidades de respostas às três vertentes da pesquisa. $\mathrm{O}$ intuito foi deixar emergir vestígios das falas dos estudantes que direcionassem a análise dos resultados.

Segundo Garnica (1997, p. 116), esse momento, que é chamado de análise ideográfica,

[...] busca tornar visível a ideologia presente na descrição ingênua dos sujeitos, podendo para isso lançar mão de ideogramas ou símbolos expressando idéias.

Para o tratamento metodológico dos dados coletados, e com a finalidade de facilitar a identificação dos sujeitos da pesquisa, foram utilizados alguns indicadores que correspondiam à fala de cada estudante em um determinado trecho do grupo focal. Dessa forma, os recortes da fala do aluno 1 - A(1) foram identificados por A(1-1), A(1-2), A(13), A(1-4)..., do aluno 2 - A(2), A(2-1), A(22), $A(2-3), A(2-4) .$. , e assim sucessivamente até o aluno $10-\mathrm{A}(10)$, para organização das informações conforme as categorias eleitas.

Tal decisão foi amparada nos estudos de Bogdan e Biklen (1994), quando afirmam que na leitura dos dados repetem-se ou destacam-se certas palavras, frases, padrões de comportamento, formas dos sujeitos pensarem e acontecimentos. Com esse processo analítico buscou-se apreender a essência situada nas entrevistas, com base nas sugestões de Garnica (1997) acerca de como proceder na análise compreensiva das descrições dos sujeitos da pesquisa.

A leitura de cada fragmento permitiu o desvelamento de um sentido significativo em cada frase, palavra, evidenciando um pouco mais o que os estudantes queriam expressar em seus discursos. Foram apontados aspectos comuns que emergiram com maior destaque em busca da similaridade. Sendo assim, ao realizar a análise das textualizações, a observação fixou-se sobre a existência de algumas proximidades entre os depoimentos. Com isso, alguns dados foram destacados e denominados "Unidades de Significado" (US).

A construção das unidades de significação contribui para a compreensão dos discursos dos sujeitos de pesquisa. Para Martins e Bicudo (1989, p. 99 apud GARNICA, 1997),

[...] é impossível analisar um texto inteiro simultaneamente, torna-se necessário dividi-lo em unidades. [...] as unidades de significado são discriminações espontaneamente percebidas nas descrições dos sujeitos quando o pesquisador assume uma atitude psicológica e a certeza de que o texto é um exemplo do fenômeno pesquisado. [...] As unidades de significado [...] também não estão prontas no texto. Existem somente em relação à atitude, disposição e perspectiva do pesquisador.

Dessa forma, é importante destacar que esses recortes, eleitos como significativos, podem variar de pesquisador para pesquisador, dependendo das vertentes e do foco da pesquisa. Após extrair as unidades de significado, ocorreu a identificação das convergências, agrupando-as de forma conveniente. Esse reagrupamento "é feito com base na análise das divergências e convergências expressas pelas unidades de significado, estando vinculada, ainda, a interpretações que o pesquisador faz para obter cada uma dessas convergências ou divergências” (GARNICA, 1997, p. 117). 
A partir das expressões sintetizadas encontradas no momento desse reagrupamento, houve uma reflexão na busca de uma aproximação à compreensão do fenômeno pesquisado, constituindo as categorias de análise - que revelam indicadores de como se dá o consumo de tecnologias por estudantes do $9^{\circ}$ ano do Ensino Fundamental em três vertentes: consumo de tecnologia para uso pessoal, consumo de tecnologia na escola e conhecimento sobre o descarte do lixo eletrônico.

Os dados obtidos na pesquisa foram analisados com a preocupação permanente de serem considerados como situações do mundo-vida dos entrevistados, tendo, portanto, como origem e contribuição as experiências cotidianas dos alunos participantes.

Por fim, a abordagem dialética sugerida por Lima (2001) contribuiu para despir e/ou mesmo retirar nossas lentes impregnadas de conceitos e/ou preconceitos, possibilitando-nos analisar fatos e/ou situações de maneira justa e coerente. Colaborou, também, para concretizarmos a intenção de lançar sobre os fatos o nosso olhar como estratégia alternativa de educação crítica, a fim de que pudéssemos, dentro de um movimento reflexivo, assentar simultaneamente as bases empírica e existencial de nossa pesquisa.

A base empírica refere-se à descrição obtida, apresenta-se como objeto de reflexão; ou seja, as informações advindas de outros mundos vividos passam a ser, nesse momento, o nosso mundo vivencial. A base existencial está relacionada à reflexão desenvolvida pelos pesquisadores sobre as descrições obtidas por meio dos sujeitos (GOMÉZ, 1992).

\section{O consumo das tecnologias da informação e da comunicação apreendido por técnicas qualitativas de pesquisa}

Como destacado, de posse dos dados, ressaltou-se a essência de cada discurso a fim de elaborar as Unidades de Significado (US) e agrupá-las, aproximando os dados convergentes. Segundo Garnica (1997, p. 117), “é a partir desses agrupamentos que o pesquisador passa a sua segunda fase de análise, a nomotética, quando a investigação dos individuais, feita pelo estudo e seleção das unidades de significado, é ultrapassada pela esfera do geral”.

Desse agrupamento evidenciaram-se três categorias, intituladas "Categorias de Análise”, que se constituem em uma síntese que teve por objetivo integrar as ideias gerais desveladas através de uma descrição consistente da estrutura situada a partir do problema de pesquisa. São elas:

\section{“O consumo dos jovens e as TIC"}

(US-03) Influência das tecnologias no cotidiano do jovem.

(US-04) A visão dos jovens quanto aos benefícios e malefícios da internet.

\section{"O consumo de TIC na escola"}

(US-02) A importância da escola no desenvolvimento de trabalhos que estimulem o uso de tecnologias.

(US-06) Ambiente escolar e recursos midiáticos: um trabalho coletivo necessário.

\section{"O descarte do lixo eletrônico e consu- mo responsável”}

(US-01) Consciência acerca do descarte do lixo eletrônico. 
(US-05) Consciência ecológica sobre o consumo responsável.

Os dados serão apresentados em termos de análises que têm como suporte a reflexividade obtida pelas técnicas qualitativas da pesquisa. Sua construção apoiou-se nos dados cruzados entre os obtidos no Formulário de Fluência Digital e nas categorias elaboradas enquanto unidades de significação (entrevista semiestruturada, grupo focal e filmagem de vídeo), fundamentadas nas preferências teóricas apontadas ao longo deste trabalho.

\section{O consumo dos jovens e as TIC}

Em relação à caracterização dos estudantes e consumo pessoal das TIC, a amostra foi composta de $51 \%$ de estudantes do sexo feminino e $49 \%$ do sexo masculino, sendo que a maioria (76\%) tinha 14 anos. Do total deles, apenas $5 \%$ trabalham; $95 \%$ dedicam-se somente aos estudos.

Quanto à fluência digital e uso de equipamentos, $87,1 \%$ dos estudantes possuem celular; 69,2\% têm leitor de mp3; 74,3\% dispõem de câmera digital; 82\% possuem videogame; e $100 \%$ têm computador, conforme ilustrado no Gráfico 1.

Gráfico 1 - Posse e uso de equipamentos

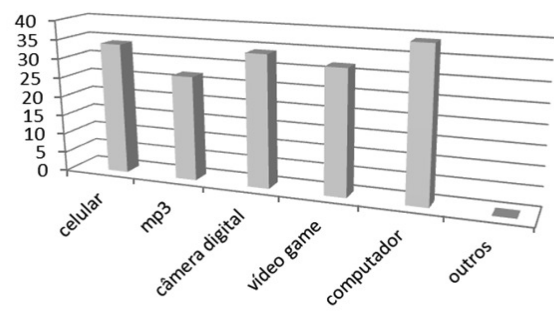

No Gráfico 2 foi identificado que $2,7 \%$ acessam a internet no trabalho e $2,7 \%$ em lan houses. Outro dado interessante é que $53,8 \%$ dos estudantes também acessam a internet em celulares. Apenas 15,3\% acessam o computador na escola, ressaltando-se que $100 \%$ possuem esse equipamento em casa.

Gráfico 2 - Local de uso do computador

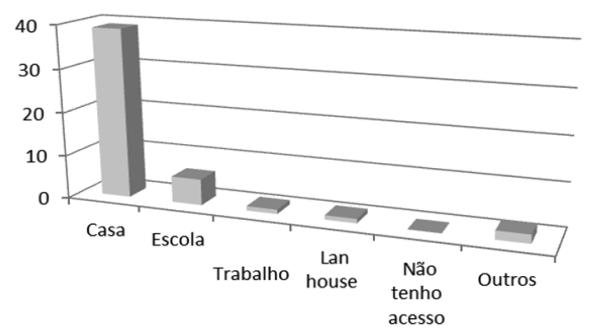

Quanto à frequência de acesso, 97\% dos alunos navegam diariamente e apenas $3 \%$ declararam que utilizam o computador semanalmente. Quanto ao uso de aplicativos tanto do computador como da internet, constatou-se que $85 \%$ usam o processador de textos; $100 \%$ pesquisam na internet; $97 \%$ enviam e recebem mensagens por e-mail; $90 \%$ já utilizaram editor de apresentações; 85\% conseguem incorporar imagens e tabelas a um arquivo; $69 \%$ usam e criam materiais multimídia; 69\% utilizam planilhas eletrônicas; $87 \%$ sabem instalar ou remover programas e softwares de computador; e $49 \%$ já criaram páginas na web.

Tal fluência digital justifica as características da geração Y (nativos digitais), considerando que ser digitalmente fluente envolve não apenas saber como usar ferramentas tecnológicas, mas também saber como construir coisas significativas com essas ferramentas (PAPERT; RESNICK, 1995). Os dados evidenciam que os alunos, sujeitos da pesquisa, em sua grande maioria, podem ser considerados fluentes digitais. 
Durante as discussões no grupo focal constatou-se que, em relação à categoria “Consumo dos Jovens e as TIC”, a internet causa fascínio aos estudantes. Eles apontaram a facilidade de comunicação oportunizada pelas redes sociais.

O twitter é um miniblog [...]. O twitter dá para conversar com algum famoso [...]. Eu já fiquei vinte e quatro horas no computador. Eu sô muito viciada no Twitter [...]. Eu tenho muitos amigos. Eu tenho, ó, amiga da Bahia, amigo do Rio de Janeiro. Tô viciada e fico o dia inteiro. (Aluno 7)

Com relação ao consumo na web, constatou-se que os estudantes são consumidores ativos. Dentre os itens de consumo adquiridos virtualmente estão: celular, roupas, computador, tênis, livros e CDs.

A leitura reflexiva dos dados permitiu observar uma dependência que se evidencia na relação ser humano-máquina, bem como os perigos provenientes dessa relação. Há consciência, por parte dos estudantes, dos exageros vivenciados com o consumo pessoal das TIC:

Ontem eu ganhei um celular novo e mexi no computador de noite. Eu entrei rapidinho no Orkut, MSN. Meu Twitter eu não tenho mais, foi hackeado [...]. Fiquei uma meia hora. (Aluno 1)

Ah, sei lá. Fiquei lá assistindo televisão uns 10 minutos, depois fiquei no computador a tarde inteira. Aí, depois fui pra igreja. Voltei à noite, arrumei meu material. Não tinha nada para fazer e fui para o computador de novo. (Aluno 3)

Obter mais dados por intermédio da filmagem, segundo Kohatsu (2007), indo além dos registros em texto escrito, tem o poder de convencer o leitor de que as palavras traduzem e decifram a verdade, as imagens visuais elevam em infinita potência o poder de convencimento. "Mais do que prova irrefutável do fato ocorrido, tomam lugar do próprio fato, confundindo o receptor mais desatento" (KOHATSU, 2007, p. 65).

Na pesquisa ora apresentada, não foram poucas as oportunidades de observação dos risos, dos sobrecenhos, ora demonstrando curiosidade ou surpresa, ora indignação e revolta; dos acenos de cabeça, ora aceitando, ora questionando ou negando a fala de um colega. São aspectos fundamentais que atestam o valor e a relevância da filmagem como técnica qualitativa de pesquisa. A imagem, segundo Bittencourt (1998, p. 198), “pode contribuir para a captura de aspectos visuais que transcendem a capacidade de representação da escrita”.

O questionário informou sobre a frequência de acesso à internet; entretanto, foi com a técnica do grupo focal e com a filmagem que se detectaram questões relacionadas aos detalhes desses acessos e à responsabilidade da família quanto a isso, como se pode constatar nas seguintes vozes:

Nos finais de semana, geralmente, saio com a minha família e tal, é nos dias da semana que eu costumo mexer no computador e esse tipo de coisa. Passo a tarde inteira no computador também. Eu fico umas 4 ou 5 horas no computador [...]. Às vezes eu fico só no Orkut, twitter. (Aluno 5)

É, eu acordei ao meio dia, aí eu fiquei no computador, aí eu saí as sete, fui para a igreja, voltei e fiquei até as três... Eu já fiquei vinte e quatro horas no computador. Eu sô muito viciado no Twitter. (Aluno 7)

Cheguei em casa, aí eu liguei o som, eu liguei a TV também, assisti um pouco de TV, aí eu fui tomar banho, aí fiquei das sete até as nove no computador. Entrei no twitter, Orkut, num site, num blog lá. Só aí eu fui dormir, tomei banho e fui dormir de novo. (Aluno 8) 
Outro dado revelador sobre o local do computador na casa dos alunos foi obtido pelo grupo focal quando ocorreram afirmações como estas:

O notebook fica no meu quarto e o computador no escritório [...]. (Aluno 7)

Eu acordei às três horas. Computador eu deixo ligado, não desligo, deixo só no modo de espera. (Aluno 10)

Em relação à postura da família, os estudantes revelaram o seguinte:

Meu pai enche o saco demais. [...] uma vez eu estava com minha amiga em meu quarto, a gente tava fazendo twitcam. Aí a gente esqueceu ligada. Minha amiga se trocando lá, eu estava no banheiro, ela tava se trocando lá na frente da cama, ficou mil acesso, todo mundo viu. (Aluno 7)

Chega no meu orkut e fala "que é isso filho”. Mó chato mesmo. (Aluno 2)

\section{O consumo de TIC na escola}

Ficou evidente pelo questionário que não há uso frequente dos computadores na escola, pois $72 \%$ dos alunos responderam que não têm acesso à sala de informática com seus professores. A diretora da escola justifica o fato alegando que a informática faz parte da grade curricular apenas dos $1^{\circ} \mathrm{e}$ $5^{\circ}$ anos do Ensino Fundamental. Além dessas turmas, os estudantes do curso técnico "Informática para Internet” também fazem uso prioritário dos computadores da escola com o professor de informática, conforme informações apresentadas no Gráfico 3.
Gráfico 3 - Uso da sala de informática

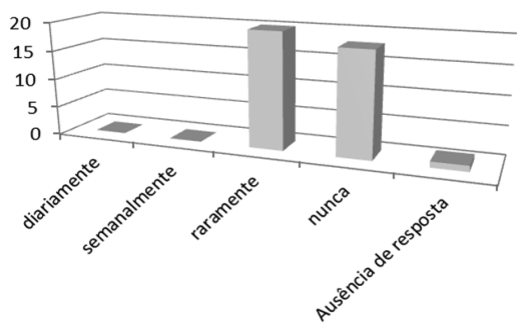

Dessa forma, baseando-se na categoria "O consumo de TIC na escola”, foi observado que a escola, embora com três salas de informática à disposição dos alunos, prioriza seu uso para anos escolares determinados e atividades curriculares ligadas à opção de cursos técnicos.

Em contrapartida, embora a escola tenha feito suas opções de uso da sala de informática, quando os alunos são abordados sobre o uso da internet nos estudos e pesquisas escolares por disciplinas, é notável a percepção da existência de estímulos dos professores que sugerem temas interessantes e complementares ao conteúdo curricular regular, conforme demonstrado nos Gráficos 4 e 5 .

Gráfico 4 - Disciplinas e pesquisa na internet

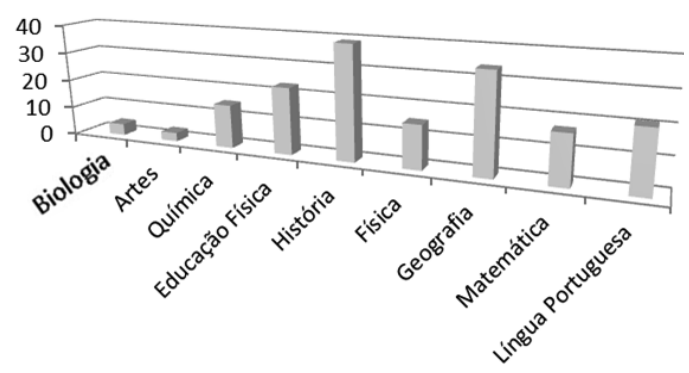

É interessante observar que há um desnível entre a frequência com que pesquisas e estudos complementares são realizados, independentes da sugestão dos professores. A maior frequência situa-se entre Geografia 
(87,1\%) e História (100\%); a menor situa-se entre as disciplinas de Biologia e Artes.

Gráfico 5 - Temas pesquisados na internet

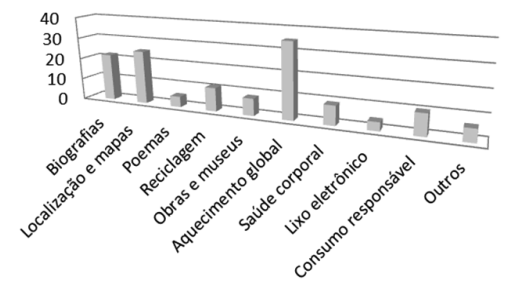

Entre os temas sugeridos pelos professores são encontrados com maior frequência os da atualidade, como aquecimento global (89,7\%), localização e mapas $(64,1 \%)$, o que revela certa tendência de que os estudos em Geografia e História apontados pela questão anterior são corroborados. É importante destacar que os itens "reciclagem”, "consumo responsável" e "lixo eletrônico" estiveram presentes no rol de temas do Gráfico 5, pois além de fazerem parte do foco desta pesquisa, já eram trabalhados pelos professores no cotidiano escolar.

Em relação à categoria "Consumo das TIC na Escola”, sob a perspectiva de entrevista semiestruturada e grupo focal, muitos dos dados acima coletados são confirmados pelos estudantes, configurando-se a triangulação da pesquisa. Para ilustrar a voz dos pesquisados seguem trechos, palavras e algumas representações captadas pelo vídeo, extraídas das perguntas do roteiro da entrevista semiestruturada: “Quando vocês estão aqui na escola, vocês acessam a internet de alguma forma? Vocês têm projeto na sala de informática?”

A maioria dos pesquisados afirmou que não utiliza computadores na escola. Outros destacaram que usam os celulares no recreio, para acessar a internet e twittar. $\mathrm{Na}$ voz do aluno 8, encontram-se os seguintes argumentos e justificativas: "Não, quando a gente tem que fazer, aí a gente pede para o professor, traz o notebook, aí a gente pesquisa. Depende do professor também se deixa ou não”.

Embora 70\% dos participantes do grupo focal tenham declarado que possuem notebook, não é frequente a autorização de seu uso em sala de aula, aspecto confirmado pelo vídeo, através da expressão corporal. " $E$ outro jeito de aprender, né? Ah, porque não fica maçante, o professor não fica falando, falando, falando" (Aluno 8). "É mais legal” (Aluno 6). "Porque não fica aquela coisa chata [...]. A gente mexeu uma vez no computador da escola” (Aluno 4).

\section{O descarte do lixo eletrônico e consumo responsável}

Os dados quantitativos obtidos pelo questionário não revelaram detalhes sobre a consciência ecológica, sobre a proteção do meio ambiente através de consumo responsável e nem mesmo quanto à questão do descarte do lixo eletrônico. Entretanto, 28,2\% dos alunos já pesquisaram sobre reciclagem; $25,1 \%$ sobre consumo responsável; e 10,2\% sobre lixo eletrônico.

Durante o grupo focal, em relação à categoria "O descarte do lixo eletrônico e consumo responsável”, os estudantes revelaram consciência ecológica apurada, tecendo críticas sobre a dificuldade do descarte do lixo eletrônico. Muitos repassam para os irmãos menores, outros vendem ou vão deixando os celulares e outros equipamentos eletrônicos não utilizados (cartuchos, impressoras, computadores, celulares) guardados em casa. A maioria dos alunos pesquisados reconhece os perigos e malefícios causados pelo lixo eletrônico ao meio ambiente, mas 
desconhece local onde o descarte desse lixo possa ser realizado.

[...] ele vaza, né? Polui e pode contaminar os lençóis freáticos. (Aluno 8)

Deve sair algum óleo. (Aluno 1)

Vai prá camada de ozônio [...]. O lixo é queimado. É. Vai para a terra e, sei lá, absorve. (Aluno 7)

Vai para o lixo comum, aí trituram [...]. Vai para o solo [...]. Sai gases. (Aluno 4)

A filmagem revelou desconhecimento de muitos detalhes sobre o descarte do lixo eletrônico, confirmando a reduzida frequência de pesquisa sobre o tema, observada pelo questionário. Entretanto, os acenos positivos dos alunos com a cabeça, suas confirmações com palavras e murmúrios durante a discussão transformaram o grupo focal em algo motivador e potencialmente gerador de transformações sobre a postura em relação a um consumo responsável, não só de lixo eletrônico como de resíduos orgânicos e inorgânicos.

Quando abordados sobre de quem seria a responsabilidade pelos desastres ecológicos, como não ter orientações sobre o descarte correto do lixo eletrônico, não ter locais adequados e outras providências, todos os alunos afirmaram categoricamente: "Nós somos os responsáveis”. E ainda arriscaram alternativas para solucionar tal problema:

Acho que as empresas que vendem deveriam recolher e fazer outros ou então reaproveitar. A Vivo faz isso. (Aluno 8)

No meu prédio tem um tipo de uma caixa lá na portaria que é do Santander. Aí dá para você colocar pilha, celular. (Aluno 1)

Meu condomínio também tem, mas não tem marca não [...]. Minha mãe manda reciclar lá em casa. É maior chato ter que ficar separando, mas minha mãe obriga, né? (Aluno 7)

Os alunos atestaram que nunca estudaram o tema consumo responsável, embora já tenham ouvido falar sobre ele, e comentaram o que viram na mídia de massa sobre a diminuição das sacolas plásticas. $\mathrm{O}$ aluno 7 afirmou: "Eles estão fazendo mais barato para quem leva a sacolinha de casa... do Walmart”. E o aluno 5 disse: “É, tem aquelas sacolas ecológicas. Levam sempre uma sacola de pano”.

\section{Algumas implicações educacionais sobre metodologia qualitativa de pesquisa e sobre o tema "Consumo"}

\section{Sobre a consciência do consumo responsável das TIC: malefícios e benefícios}

A triangulação das técnicas utilizadas foi potencialmente reveladora e confirmou sua capacidade de complementaridade dos dados e possibilidade de reflexividade não apenas para os pesquisadores como também para o corpo diretivo da escola e, principalmente, para os estudantes que participaram da pesquisa. Na finalização da coleta de dados, a vocação de pesquisadores-educadores prevaleceu. Sentiu-se necessidade de síntese, quando alguns problemas foram colocados pelos alunos participantes da pesquisa. Solicitou-se, então, um registro sobre os benefícios e malefícios da internet e a representação metafórica em forma de um animal, cujas características se aproximassem do que significava a internet para eles.

Os estudantes atenderam prontamente a essa solicitação não prevista na entrevista semiestruturada e a desenvolveram com 
muito entusiasmo e motivação. Como benefícios, $70 \%$ dos alunos afirmaram que não conseguem viver sem internet (70\%), devido à facilidade de acesso a qualquer informação e conteúdo; $100 \%$ deles ressaltaram a magnitude da comunicação potencializada pela internet; $50 \%$ destacaram as facilidades que a internet proporciona às pesquisas escolares; 90\% apontaram a dimensão de entretenimento por meio da oferta dos games, músicas e vídeos, e poucos se atentaram para o desenvolvimento de habilidades.

Ir até a biblioteca. Falei "vai se lascar!". Ir até a biblioteca, maior rolê até lá. Abrir livro por livro. Nem morto! (Aluno 2)

Desenvolve a inteligência, a tecnologia [...]. Exercita o cérebro. Por exemplo, um jogo de estratégias, você tem que pensar pra fazer certa coisa. (Aluno 10)
É, lá no google, wikipédia abriu já, dois segundos [...]. Mas internet deixa burro! (Aluno 7)

Os estudantes que participaram do grupo focal apontaram os seguintes malefícios da internet: pedofilia e pornografia; vício, sedentarismo e distração; dispersão; perda da noção entre o público e o privado, com invasão da privacidade; convivência com posições preconceituosas e presença de sites não confiáveis.

O uso da técnica de diagramas também colaborou para a obtenção de dados importantes para a pesquisa. Segundo Leite (1998, p. 43), o "texto verbal e o visual são polissêmicos e complementares”. Quanto à representação metafórica da internet na figura de algum animal, foi produzido o Quadro 1 com suas características.

Quadro 1 - Diagramas representativos do Consumo da Internet sugeridos pelos estudantes do Ensino Fundamental

\begin{tabular}{|l|l|}
\hline & \multicolumn{1}{|c|}{ Características } \\
\hline
\end{tabular}




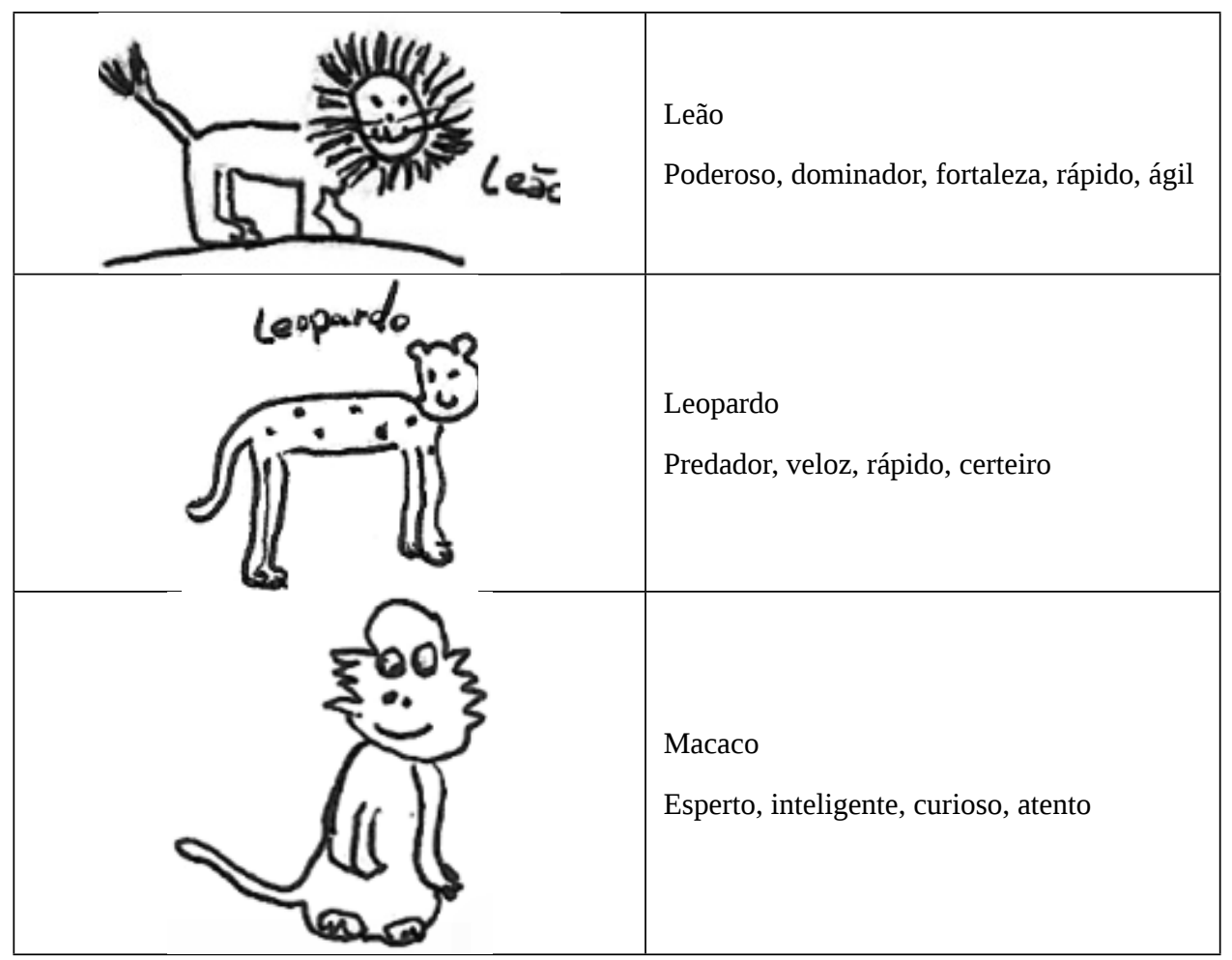

O conjunto de dados quantitativos e qualitativos comprovou que há $100 \%$ de acesso às tecnologias digitais por parte dos alunos; o uso prioritário pessoal caracterizase pelo acesso às redes sociais como forma de entretenimento (Orkut e Twitter); a escola não utiliza as tecnologias digitais na grade curricular semanal das aulas, mas sim em projetos esporádicos. A pesquisa teve como fato revelador a preocupação ecológica dos jovens sobre a necessidade de providências governamentais quanto ao descarte e coleta seletiva de lixo eletrônico e aos perigos de acesso à internet de forma acrítica.

\section{Sobre a potencialidade das técnicas híbridas da pesquisa qualitativa}

A seleção de técnicas híbridas de pesquisa confirmou que uma das vantagens da utilização do questionário como técnica de pesquisa foi o fato de se correr menor risco de distorção, pela não influência dos pesquisadores; de se atingir maior número de pessoas simultaneamente, por constituir um meio rápido de obtenção de informações; de se ter maior liberdade nas respostas, em razão do anonimato (GIL, 1994).

O desenvolvimento da entrevista semiestruturada contribuiu para a triangulação dos métodos, o que permitiu a corroboração dos resultados do questionário. Boni e Quaresma (2005) destacam que uma das vantagens da entrevista semiestruturada é a sua elasticidade quanto à duração. Durante o exercício desta investigação essa vantagem foi comprovada, tendo em vista que certas questões foram claramente respondidas, outras exigiram uma cobertura mais profunda e houve a necessidade de questões complementares obtidas por outros dados. 
O planejamento de questões norteadoras foi essencial para a condução segura do grupo focal e o clima estabelecido pelos pesquisadores também favoreceu respostas espontâneas, fidedignas e válidas, pois foi constatado que as respostas coletadas pelo questionário, respondido anonimamente, foram corroboradas na entrevista.

A técnica de filmagem do grupo focal caracterizou-se como um registro importante no processo de transcrição das falas correspondentes a cada estudante. Além disso, conforme Hassen et al. (2000, p. 718), "o ambiente, os comportamentos individuais e grupais, a linguagem não verbal, a sequência, a temporalidade em que ocorrem os eventos são fundamentais" como subsídios para interpretação posterior dos mesmos. A possibilidade de rever o registro da dinâmica do grupo focal fez com que os pesquisadores se distanciassem das emoções e atitudes presentes do momento e identificassem outros aspectos, sob a perspectiva de um novo olhar.

Pinheiro, Kakehashi e Angelo (2005), bem como Boni e Quaresma (2005), alertam para o fato de que as pessoas podem modificar seu comportamento - ficarem inibidas ou constrangidas - diante das câmeras, na presença do gravador, ou quando são observadas. Porém, no momento do grupo focal, e ao rever o vídeo, foi possível notar que os participantes estavam à vontade. Foram raros os momentos em que eles olharam para a câmera; a sua concentração estava geralmente voltada para o condutor do grupo focal.

Esta pesquisa não se limitou à utilização de instrumentos fechados, de quadros de categorias previamente definidas e de técnicas de análise de dados que levassem ou não tratamento estatístico. Houve o entendimento de que uma pesquisa qualitativa não trata apenas da escolha de instrumentos e técnicas, devido à importância de selecionar uma determinada concepção de ciência e referenciais teóricos para interpretar os resultados. As técnicas utilizadas não ficaram descoladas dessas concepções epistemológicas. De acordo com Sánches Gamboa (2003), se reduzirmos essas escolhas apenas a dois modelos epistemológicos, um relacionado com as técnicas quantitativas e outro com as técnicas qualitativas, passamos de um falso dualismo técnico para um falso dualismo epistemológico.

Em relação à coleta e tratamento de informações, a pesquisa confirmou que o uso de mais de uma técnica e seus instrumentos - como entrevistas semiestruturadas, filmagens, grupo focal - não se fecha à interpretação num único sentido (paráfrase). Ao contrário: permite o jogo de sentidos (polissemia), como entende Sánches Gamboa (2003). Houve, portanto, necessidade de se recorrer à elaboração de um quadro de conceitos ou categorias que permitiram a definição de um horizonte de interpretação. Na busca dos sentidos, além desse horizonte, também foi possível captar pela filmagem os contextos sociais e culturais dos estudantes sobre o consumo das tecnologias de informação e de comunicação. As palavras, os gestos, os símbolos, as figuras, as diversas expressões e manifestações contribuíram sobremaneira para a compreensão e entendimento dos dois focos da pesquisa: a temática sobre o consumo e as contribuições metodológicas das técnicas qualitativas.

A pesquisa em equipe foi extremamente relevante para compreender o problema, diagnosticar uma situação problemática e elaborar uma resposta diante de tantos elementos técnicos articulados a um procedimento científico e a uma lógica do conhecimento. O que importou para a equipe de pesquisadores foi a condução do processo, e esta veio da concepção epistemológica construída durante o planejamento e a realização 
da pesquisa. Ficou patente no processo que a questão da qualidade da pesquisa depende mais da lógica das articulações das formas de abordar os problemas, dos processos da elaboração das respostas para esses problemas, das formas de compreender a ciência e a produção do conhecimento, do que das escolhas técnicas (SÁNCHES GAMBOA, 2003).

Essa investigação proporcionou um campo muito rico e gratificante para a formação dos pesquisadores quanto à compreensão dos conflitos gerados entre pesquisa qualitativa e quantitativa, entre subjetividade e objetividade, e quanto à seleção de técnicas e procedimentos múltiplos que permitissem a reflexividade e a triangulação, definidas por critérios que se aproximassem com cientificidade da verdade.

\section{Referências}

BITTENCOURT, L. A. Algumas considerações sobre o uso da imagem fotográfica na pesquisa antropológica. In: FELDMAN-BIANCO, B.; LEITE, $M$. (Orgs.). Desafios da imagem: fotografia, iconografia e vídeo nas ciências sociais. Campinas: Papirus, 1998.

BOGDAN, R.; BIKLEN, S. Investigação qualitativa em educação. Lisboa: Porto Editora, 1994.

BONI, V.; QUARESMA, S. J. Aprendendo a entrevistar: como fazer entrevistas em ciências sociais. Em Tese, Santa Catarina, v. 2, n. 1 (3), p. 68-80, 2005.

CARLINI-COTRIM, B. Potenciali-dades da técnica qualitativa grupo focal em investigações sobre abuso de substâncias. Revista Saúde Pública, São Paulo, v. 30, n. 3, Jun. 1996. Disponível em <http:// www.scielosp.org/pdf/rsp/v30n3/5075.pdf>. Acesso em 03 de dez. 2010.

CHIZZOTTI, A. A pesquisa qualitativa em ciências humanas e sociais: evolução e desafios. Revista Portuguesa de Educação, Portugal, v. 16, n. 2, p. 221-236, 2003.

FLICK, U. Uma introdução à pesquisa qualitativa. Porto Alegre: Bookman, 2002.

GARNICA, A. V. M. Algumas notas sobre pesquisa qualitativa e fenomenologia. Interface: Comunicação, Saúde, Educação, Botucatu, v. 1, n. 1, p. 109-122, ago. 1997.

GIL, A. C. Como elaborar projetos de pesquisa. 3. ed. São Paulo: Atlas, 1994.

GOMÉZ, A. P. O pensamento prático do professor. In: NÓVOA, A. (Org.). Os professores e sua formação. Lisboa: Publicações Dom Quixote, 1992.

GÜNTHER, H. Pesquisa qualitativa versus pesquisa quantitativa: esta é a questão? Psicologia: Teoria e Pesquisa, Brasília, v. 22, n. 2, p. 201-210, mai/ago 2006.

HASSEN, M. de N. A.; VÍCTORA, C. G.; KNAUTH, D. R. Pesquisa qualitativa em saúde: uma introdução ao tema. Porto Alegre: Tomo, 2000.

IERVOLINO, S. A.; PELICIONI, M. C. F. A utilização do grupo focal como metodologia qualitativa na promoção da saúde. Revista Escola de Enfermagem USP, São Paulo, v. 35, n. 2, p. 115-121, 2001.

JICK, T. D. Mixing qualitative and quantitative methods: trangulation in action. Administrative Science Quarterly, Cornell, v. 24, n. 4, p. 602-611, dez 1979,

KINDON, S. Participatory video in geographic research: a feminist practice of looking? Area, v. 35, n. 2, p. 142-153, jun. 2003. 
KESBY, M. Participatory diagramming: deploying qualitative methods through an action research epistemology. Area, v. 32, n. 4, p. 423-435, dez 2000.

KOHATSU, L. N. O uso do vídeo na pesquisa de tipo etnográfico: uma discussão sobre o método. Psicologia da Educação, São Paulo, n. 25, dez. 2007. Disponível em <http:// pepsic.homolog.bvsalud.org/pdf/psie/n25/ v25a04.pdf $>$. Acesso em 05 dez. 2010.

LAKATOS, E. M., MARCONI, Marina de Andrade. Técnicas de pesquisa. 3. ed. São Paulo: Atlas, 1996.

LEITE, M. M. Texto visual e texto verbal. In: FELDMAN-BIANCO, Bela; LEITE, Miriam Moreira (Org.). Desafios da imagem: fotografia, iconografia e vídeo nas ciências sociais. Campinas: Papirus, 1998.

LIMA, L. A escola como organização educativa. São Paulo: Cortez, 2001.

MINAYO, M. C. de S. (Org.) Pesquisa social: teoria, método e criatividade. 18. ed. Petrópolis: Vozes, 2001.

PAPERT, S.; RESNICK, Mitchel. Technological fluency and the representation of knowledge. Proposal to the National Science Foundation. MIT MediaLab, 1995.

PARFITT, J. Questionnaire design and sampling. In: FLOWERDEW, Robin; MARTIN, David (Ed.). Methods in human geography: a guide for students doing a research project. England: Pearson Education Limited. p. 78-109, 2005.

PINHEIRO, E. M.; KAKEHASHI, T. Y.; ANGELO, M. O uso de filmagem em pesquisas qualitativas. Revista Latino Americana de Enfermagem, São Paulo, v. 13, n. 5, p. 717-722, set./out. 2005.
PINK, S. M. visualising, moremethodologies: on vídeo, reflexivity and qualitative research. The Sociological Review, v. 48, n. 4, p. 586599, nov. 2001.

SÁNCHES GAMBOA, S. Pesquisa qualitativa: superando tecnicismos e falsos dualismos. Contrapontos. v. 3, n. 3, p. 393-405. Itajai, set./dez. 2003.

Enviado em: 23/02/2011

Aceito em: 15/06/2011 